\title{
Panqualityism, Awareness and the Explanatory Gap
}

\author{
Jakub Mihálik ${ }^{1,2}$ (D)
}

Received: 14 June 2019 / Accepted: 30 March 2020 / Published online: 14 April 2020

(c) The Author(s) 2020

\begin{abstract}
According to panqualityism, a form of Russellian monism defended by Sam Coleman and others, consciousness is grounded in fundamental qualities, i.e. unexperienced qualia. Despite panqualityism's significant promise, according to David Chalmers panqualityism fails as a theory of consciousness since the reductive approach to awareness of qualities it proposes fails to account for the specific phenomenology associated with awareness. I investigate Coleman's reasoning against this kind of phenomenology and conclude that he successfully shows that its existence is controversial, and so Chalmers's critique is inconclusive. I then present a critique of panqualityism that avoids this controversial posit, arguing that the panqualityist treatment of awareness faces an explanatory gap, failing to account for the intimate cognitive access to qualities which we are afforded, i.e. for our 'strong awareness' of qualities. The real worry for panqualityists is thus not the contested phenomenology of awareness, which Chalmers relies on, but rather the special way in which we are aware of qualities.
\end{abstract}

In the debate about phenomenal consciousness, Russellian monism, the view on which fundamental microphysical entities have special intrinsic properties that are directly relevant to the production of consciousness in organized systems, is becoming increasingly popular. The reason for the view's popularity is that it provides persuasive replies to the main anti-materialist arguments while not facing the problem of mental causation that dualism struggles with (Chalmers 2015; Stoljar 2014; Goff 2017). Chalmers (2017) has suggested that an especially promising variety of Russellian monism is panqualityism, an approach inspired by the views of Russell himself (1954), Feigl (1958/1967) and Mach (1959) and recently defended by Coleman

Jakub Mihálik

jakubmihalik@yahoo.com

1 The Czech Academy of Sciences, Institute of Philosophy, Jilská 1, 11000 Prague 1, Czech Republic

2 Department of Philosophy, University of Hertfordshire, de Havilland Campus, AL10 9AB, Hatfield, Hertfordshire, UK 
(2014, 2017), since-unlike other main varieties of Russellian monism-the view does not face the combination problem in its most serious forms.

According to panqualityism, consciousness is grounded ${ }^{1}$ in organized fundamental qualities. Here qualities are to be distinguished from phenomenal properties, i.e. properties of conscious states in virtue of which there is something it's like for one to be in these states (Nagel 1974). To understand the notion of a quality, recall experiences of looking at ripe strawberries or having a migraine headache and conceive of the redness or ache presented in these experiences without their being experienced. Qualities are just these intrinsic properties which our experiences present us with, conceived as unexperienced. Using Coleman's phrase, qualities are unexperienced qualia (Coleman 2017, p. 249).

Despite the promise of panqualityism, Chalmers argues that the view fails as a theory of consciousness when confronted with a version of the conceivability argument. While the original conceivability argument invites us to deduce the falsity of physicalism from the conceivability of philosophical zombies, our physical replicas without consciousness (Chalmers 1996), the conceivability argument against panqualityism invites us to deduce the falsity of panqualityism from the conceivability of qualitative zombies (q-zombies). Here q-zombies are creatures which instantiate appropriately organised qualities in their brains but lack consciousness because they are not aware of these qualities (Chalmers 2015). According to Chalmers, q-zombies are conceivable because panqualityism fails to account for the specific phenomenology associated with awareness (awareness-phenomenology). If Chalmers is right, the conceivability argument is a metaphorical double-edged sword, with one version of the argument motivating panqualityism, but another version ruling it out. In reply, Coleman (2017, p. 270) insists that the q-zombie-based threat for panqualityism can be averted as, contra Chalmers, awareness itself does not involve any phenomenology.

I shall investigate Coleman's reasoning against the phenomenology of awareness and conclude that he successfully shows that its existence is controversial. I shall then argue, however, that the issue of awareness-phenomenology which Chalmers and Coleman contest is inessential to the main difficulty with panqualityism, which is more fundamental than both participants in this debate suppose. According to my critique, panqualityism provides inadequate resources to account for our experience of qualities, which is why the view faces an explanatory gap between organized qualities and the relevant sort of awareness of these qualities which I call strong awareness. Crucially, this gap does not depend on the contested posit of awarenessphenomenology which Chalmers's critique relies on. My critique of panqualityism is thus dialectically stronger than Chalmers's.

I flesh out my characterization of Russellian monism in (1) and delineate the relation of panqualityism to other varieties of this view in (2). In (3) I describe Chalmers's critique of panqualityism and in (4) I show that it relies on a highly controversial posit of awareness-phenomenology. After discussing the details of Coleman's 'quotational' account of awareness in (5), I advance my own critique of it in (6)

\footnotetext{
${ }^{1}$ Here A-properties ground B-properties iff truths about B-properties hold in virtue of truths about A-properties holding.
} 
to (8), arguing that it faces a specific explanatory gap which renders panqualityism subject to a variety of the conceivability argument. In (9), I consider the prospects of combining panqualityism with other accounts of awareness, concluding that the present critique extends to all forms of panqualityism which appeal to reductive accounts of awareness while versions of the view that appeal to non-reductive accounts of awareness face considerable independent challenges.

\section{The Promise of Russellian Monism}

Chalmers's 'hard problem', i.e. the challenge to explain how physical brain processes produce consciousness (Chalmers 1995), looks particularly vivid once we appreciate that physics characterizes its basic entities purely in terms of structure and dynamics. All we learn from physics about basic physical entities are their spatiotemporal properties, their behavioural roles and how these properties change over time (Chalmers 2010, p. 120). Philip Goff, for example, writes:

Physics tells us that an electron has negative charge. What does physics have to tell us about negative charge? Rough and ready answer: things with negative charge repel other things with negative charge and attract other things with positive charge. [...] Physics tells us nothing about what an electron is beyond what it does. (Goff 2017, p. 136).

Consciousness, however, isn't purely structural. Apart from its structure, the experience of seeing a ripe strawberry, for example, appears to involve a specific intrinsic property, ${ }^{2}$ best described as what the phenomenal redness is like in and of itself. This intrinsic property seems irreducible to structural properties. If, then, the structural description fully expresses what microphysical entities are, they seem hopelessly unfit to explain consciousness with its intrinsic properties; they are just the wrong sort of material, hence the hard problem.

Russellian monists, however, deny that the structural description is exhaustive. While claiming that

(A) physics only describes structural properties of microphysical entities,

they hold that

(B) structural properties are realised by quiddities.

The structural description of microphysical entities then leaves out quiddities, i.e. the fundamental intrinsic properties of these entities. ${ }^{3}$

Moreover, importantly, Russellian monists hold that

\footnotetext{
${ }^{2}$ I view intrinsic properties as those properties a thing would have even if it were absolutely alone in the universe. For some worries about this characterization see e.g. Seager (2006).

${ }^{3}$ Speaking of quiddities in the plural, I assume the 'smallist' version of Russellian monism. See Goff (2017) for a holistic take on Russellian monism.
} 
(C) quiddities are directly relevant for consciousness. ${ }^{4}$

The direct relevance of quiddities for consciousness results from quiddities' being phenomenal, or protophenomenal properties (Chalmers 2015). On Russellian panpsychism, quiddities are primitive phenomenal properties (Strawson 2006, Rosenberg 2004). According to Russellian panprotopsychism, quiddities are protophenomenal properties, special intrinsic properties which, while not themselves phenomenal, jointly constitute phenomenal properties when appropriately organized. A fuller definition of protophenomenal properties, moreover, requires that truths about them and their organisation a priori entail truths about consciousness, i.e. phenomenal truths, so there is no epistemic gap between the two classes of truths (Chalmers 2015)..$^{5}$

The fact that according to both main branches of Russellian monism, quiddities are directly relevant to human-level consciousness, being its constituents, ${ }^{6}$ gives the view significant advantages over materialism and dualism. ${ }^{7}$ Consider materialism first. Russellian monism offers a straightforward reply to the conceivability argument, the most significant anti-materialist challenge (Chalmers 2010, chap. 6). The argument has the following structure, where $P$ stands for the complete set of physical truths and $Q$ stands for an arbitrary phenomenal truth such as "Jane is phenomenally conscious".

(1) $P \& \sim Q$ is conceivable.

(2) If $P \& \sim Q$ is conceivable, $P \& \sim Q$ is possible.

(3) If $P \& \sim Q$ is possible, physicalism is false.

(4) Physicalism is false.

This argument turns on an epistemic gap between physical and phenomenal truths, from which an ontological conclusion is inferred via a modal premise. More vividly, the argument tells us that the conceivability of philosophical zombies entails their possibility and thus materialism fails.

It's hard for physicalists to resist premise (1) given the apparent gap between structural truths of physics and phenomenal truths. ${ }^{8}$ Not so for Russellian monists, who think that the complete physical truth must include truths about quiddities.

\footnotetext{
4 See Alter and Nagasawa (2015) for a detailed definition of Russellian monism.

5 See Goff (2015) for a different definition.

6 I leave aside non-constitutive varieties of Russellian monism, such as emergent panpsychism [see Goff (2015)] as these arguably inherit dualism's problem with mental causation (see below).

7 See Chalmers (2015) for a detailed discussion of these advantages.

8 See, however, Dennett (1991).
} 
Call this enhanced set of physical truths $P^{*}$. Since for Russellian monists quiddities jointly constitute consciousness, they have a good reason to claim that while $P \& \sim Q$ is conceivable, $P^{*} \& \sim Q$ isn't because $P^{*}$ a priori entails $Q$. In being able to straightforwardly block the argument, Russellian monism has a distinct advantage over materialism.

Russellian monism also addresses the challenge of mental causation faced by dualism. ${ }^{9}$ On dualism, phenomenal properties are non-physical, so their causal efficacy is ruled out by the completeness of physics, the claim that physical effects have purely physical causes, which many take seriously. ${ }^{10}$ Since, however, according to Russellian monism, (proto)phenomenal properties are quiddities which play fundamental microphysical roles, we have a good reason to attribute causal powers to them (Stoljar 2001, p. 267). Moreover, since human-level consciousness is constituted by quiddities, we have a good reason to hold that it's causally efficacious too ${ }^{11}$ as constituted wholes arguably inherit causal efficacy from their constituents (Chalmers 2015, p. 257).

Russellian monism thus looks promising, with its panqualityist variety, as I shall now explain, being especially hopeful.

\section{Panqualityism and Its Merits}

Panqualityism amounts to the conjunction of (A), (B), (C) and

(D) quiddities are qualities.

Since qualities are distinct from phenomenal properties, and yet relevant to consciousness, they are strong candidates for protophenomenal properties, which would render panqualityism a form of Russellian panprotopsychism. It is, however, integral to the definition of protophenomenal properties that truths about appropriately organized systems of them a priori entail phenomenal consciousness. The fact that I instantiate a phenomenal property and so there's something it's like for me to be in a mental state a priori entails that I am conscious. No such implication holds for individual qualities which, panqualityists stipulate, can exist without anybody experiencing them. Still, panqualityists hold that truths about appropriately organized multitudes of qualities a priori entail truths about consciousness since the organization renders the organism aware of some of the qualities it instantiates.

Feigl (1958/1967, p. 91) suggests that “one area of the cortex 'taps' or 'scans' other areas", conceiving of awareness of qualities in broadly representationalist terms. Coleman $(2014,2017)$ develops this idea, embracing Rosenthal's (1997, 2005) view that we are conscious of a mental state in virtue of having a (noninferential) higher-order thought (HOT) that we are in that state. He introduces his HOT panqualityism as follows:

\footnotetext{
9 See Papineau (2002) for an argument along these lines.

10 The term is Papineau's (2002).

11 I stipulate that A-properties constitute B-properties iff A-properties wholly ground B-properties.
} 
We might envisage a panqualityist world, a web of qualities, with the HOT systems in brains, by representing other bits of these same brains, enabling consciousness of certain tiny portions of the material universe. (Coleman 2017, p. 265)

Only the qualities our HOTs represent then appear in consciousness with myriads of others remaining unexperienced. If an account of awareness along these lines is plausible, qualities are protophenomenal properties since their organisation grounds awareness of qualities and thus consciousness, which means that the a priori entailment requirement is met.

Panqualityism exhibits significant advantages over other varieties of Russellian monism. Consider non-panqualityist Russellian panprotopsychism first. Its proponents say little about protophenomenal properties (Stoljar 2001; McClelland 2013). They typically hold that protophenomenal properties are non-phenomenal, non-qualitative and yet relevant to the production of consciousness, but that leaves their nature largely unknown and we are given no clue as to why they are relevant to consciousness. It is, I suggest, a distinct advantage of panqualityism that it tells us what protophenomenal properties are and why they are relevant to consciousness.

Another challenge for non-panqualityist panprotopsychism is the non-qualityquality gap, the problem of explaining how the qualities which we are aware of are constituted by combining non-qualitative elements. It's unclear how a reddish quality, for example, could be constituted by utterly non-qualitative, colourless elements. Panqualityists do not face this gap as they hold that all qualities are either fundamental or intelligibly result from combining the fundamental ones (think mixing red and blue paint to get purple paint) (Coleman 2012), which I take to be a merit of their view.

Importantly, unlike Russellian panpsychism, panqualityism doesn't face the 'subject-combination problem' of explaining how myriads of micro-subjects combine and form human-level macro-subjects (James 1890; Chalmers 2017; Coleman 2014). The problem can be expressed as the following conceivability argument against panpsychism (Goff 2009). Here PP is the complete set of physical truths in conjunction with truths about micro-subjects and $Q$ is an arbitrary truth about macro-subjects, such as "There is at least one macro-subject".

(1) $P P \& \sim Q$ is conceivable.

(2) If $P P \& \sim Q$ is conceivable, $P P \& \sim Q$ is possible.

(3) If $P P \& \sim Q$ is possible, panpsychism is false.

(4) Panpsychism is false. 
The argument turns on an epistemic gap between truths about micro-subjects (plus structural truths), and truths about macro-subjects. The case for this subject-subject gap is strong since our conception of $n$ subjects, intricately organised, doesn't a priori entail the existence of an $n+1$ st subject. ${ }^{12}$ Panpsychists, moreover, cannot easily deny the conceivability-possibility link expressed in (2) as their usual motivation for the rejection of materialism involves a link of this sort. ${ }^{13}$

As qualities don't require subjects for their existence, the subject-subject gap doesn't harm panqualityism, which gives the view a significant advantage over Russellian panpsychism (Coleman 2014; Chalmers 2015). Since panqualityism also has important advantages over physicalism, dualism and non-panqualityist Russellian panprotopsychism, there is a strong case for taking the view seriously.

\section{Chalmers Against Panqualityism}

Despite its virtues, panqualityism faces its own conceivability argument (Chalmers 2015, pp. 273-274). Here $Q Q$ stands for the set of all truths about qualities in conjunction with structural truths, and $Q$ stands for an arbitrary phenomenal truth, such as "Jane is phenomenally conscious".

(1) $Q Q \& \sim Q$ is conceivable.

(2) If $Q Q \& \sim Q$ is conceivable, it is possible.

(3) If $Q Q \& \sim Q$ is possible, panqualityism is false.

(4) Panqualityism is false.

Here premise (1) expresses a quality-consciousness gap that can be made vivid by invoking the conceivability of qualitative zombies (q-zombies), creatures which instantiate the qualities we do and the structural properties constituting the awareness-supporting HOT mechanism, while lacking consciousness (Chalmers 2015, p. 273). If q-zombies are conceivable, the panqualityist recipe for consciousness is lacking and the view is ruled out by this argument.

The panqualityists are unlikely to question the conceivability-possibility link in (2) as their rejection of physicalism is typically motivated by a conceivabilitypossibility link of this sort. The most promising line of resistance, then, is to

\footnotetext{
12 Worse yet, Coleman (2014) argues that subject-combination is inconceivable. See Goff (2017b) for an attempt to close this gap.

13 This argument cannot be used against emergent panpsychism which, however, faces its own serious problems (see fn. 6), so I shall ignore this complication here.
} 
question premise (1). I shall now examine this line of defence, recently taken by Coleman (2017).

Initially, it is unclear how panqualityists can hold that q-zombies are inconceivable, given that they insist we can conceive of a single instance of a quality without there thereby existing consciousness of that quality. All we add in the q-zombie case, after all, is complexity and structure, which do not obviously entail consciousness. That alone, however, will not do as Coleman offers an explanation of why structure and complexity matter, viewing awareness as reducible to a HOT mechanism and ultimately to structural properties of the brain. Since q-zombies instantiate both qualities and the relevant structure, they are, Coleman holds, inconceivable and the conceivability argument against panqualityism fails.

This objection to premise (1) relies on the panqualityist blend of anti-reductionism about qualities with reductionism about awareness. The latter thesis, however, has been contested by Chalmers, who has argued that the reductive account of awareness cannot block the conceivability of q-zombies because awareness involves its own phenomenology, which cannot be reductively explained. Chalmers (2017, p. 203) writes against panqualityism:

Awareness involves phenomenology, and there are good reasons to think that no mere functional state can constitute phenomenology. For example, one can conceive of any such functional state in the absence of phenomenology, and in particular in the absence of awareness.

This consideration closely mirrors the one behind the anti-physicalist conceivability argument, which turns on the gap between organized physical goings-on and phenomenology. Here Chalmers applies the same consideration to the specific issue of phenomenology of awareness. Supposing that mere organization does not necessitate phenomenology, as the panqualityist should, and that Chalmers is right in thinking that awareness involves phenomenology, Coleman's HOT account of awareness must fail.

Chalmers's argument against panqualityism can be summarized as follows:

(1) On panqualityism, awareness is reductively explained in terms of structural properties.

(2) Awareness involves its own phenomenology.

(3) Structural properties alone do not constitute phenomenology.

(4) Awareness cannot be reductively explained in terms of structural properties. $(2+3)$

(5) Panqualityism is false. $(1+4)$

Here (1) expresses the panqualityist account of awareness and (3) is a general claim about a structure-phenomenology gap, which I argued for in Sect. 1, and which Coleman has a good reason to accept. Clearly, the real action happens in premise (2), which I shall now investigate. 


\section{The Issue of Awareness-Phenomenology}

The view that

(E) being aware of qualities involves phenomenology

is almost generally accepted. ${ }^{14}(\mathrm{E})$ is, notably, compatible with the thesis that awareness itself, while necessary for phenomenology, does not phenomenologically contribute to our overall phenomenology, which means that there is no specific awareness-phenomenology. Only the qualities we are aware of then phenomenologically contribute to our phenomenology on this view. One reason to hold that

(F) awareness makes no phenomenological contribution to phenomenology

is that one embraces the transparency of awareness thesis, which states that while we are often aware of qualities,

(G) we are never aware of awareness itself, i.e. there is no meta-awareness.

Presumably, if $(\mathrm{G})$ is plausible, then so is $(\mathrm{F})$, since it's unclear how awareness could phenomenologically contribute if we are never aware of it, as it is then utterly transparent. Arguably, something can phenomenologically contribute to our phenomenology only if we are aware of it. So $(\mathrm{G})$ plausibly entails $(\mathrm{F})$.

Chalmers's objection against panqualityism is based on his assertion that there is awareness-phenomenology, which amounts to denying (F). Chalmers (2017, p. 202, 2013, p. 347), moreover, rejects the transparency of awareness thesis (G), which makes it sensible to reject $(\mathrm{F})$ as, arguably, if we are aware of awareness, there must be something it's like to be aware of it. ${ }^{15}$ Chalmers is not alone in rejecting both (F) and (G). Inspired by Aristotle, Brentano and continental phenomenology, Uriah Kriegel suggests that all our conscious states essentially involve inner self-awareness. Kriegel (2009, p. 175) rejects (G), when he writes that

[E]ven the simplest visual experience-say, a homogenously bluish experience-folds within it an outer awareness of blue and an inner awareness of that very outer awareness.

Inner awareness of awareness is, for Kriegel, normally a constant peripheral accompaniment of outwardly oriented awareness and a constitutive aspect of our overall phenomenology, which means (F) must be false (Kriegel 2009, p. 181). The term 'constitutive' is crucial as it signifies that our phenomenology could not exist without it (Kriegel 2009, pp. 174-175). For Kriegel, then, both the qualities we are aware of and awareness itself phenomenologically contribute to our phenomenology. ${ }^{16}$

\footnotetext{
${ }^{14}$ See, however, Dennett (1991).

${ }^{15}$ Coleman (2017, p. 279, fn. 79) holds that being aware of X means that there is specific phenomenology associated with X.

${ }^{16}$ See also e.g. Montague (2017); Strawson (2017); Zahavi (1999).
} 
If there is awareness-phenomenology, Chalmers's objection applies to panqualityism, as the view cannot account for this phenomenology, and so q-zombies are conceivable and panqualityism must fail. Coleman, however, denies that there is awareness-phenomenology, holding that awareness, while necessary for phenomenology, doesn't phenomenologically contribute to it. For him, awareness is utterly transparent, being a hidden mechanism which displays qualities in consciousness. He reasons:

It is via awareness that we encounter sensory qualities and the appearances of things, but why should the faculty that presents sensory qualities to us itself make some appearance among our sensory qualities? That would be akin to the camera appearing in the periphery of every shot of a television show. (Coleman 2017, p. 270).

Coleman thus accepts $(\mathrm{F})$, which he justifies by embracing the transparency of awareness thesis $(\mathrm{G})$. Notice that the transparency thesis he is committed to is fairly strong. It states that we are never aware of our awareness, since any moment of meta-awareness would presumably involve awareness-phenomenology, and Chalmers's conceivability argument against panqualityism would then apply. Coleman's transparency thesis is thus stronger than the one famously embraced by Moore (1903), who held that while we are usually not conscious of our own consciousness, but rather only of its objects, consciousness itself can be distinguished if we look attentively enough. Coleman's transparency thesis is also stronger than those embraced by other proponents of the HOT theory, such as Rosenthal (1997) and Gennaro (2008), who deny that ordinary, non-introspective consciousness involves peripheral conscious meta-awareness while holding that in introspection we become aware of our awareness. Coleman (2017, p. 280, fn. 87) denies the possibility of this sort of introspection on phenomenological grounds.

Coleman's transparency thesis may seem implausible: is it not obvious that we are sometimes aware of our awareness? Coleman (2017, p. 271) insists that he doesn't experience any phenomenological contribution made by awareness itself, suggesting that proponents of awareness-phenomenology misclassify certain phenomenology associated with sensory qualities as awareness-phenomenology. Particularly prone to such misclassification, he suggests, are qualities associated with mental effort, with the first-order thought 'I am aware', or with experiencing one's self as an embodied agent. ${ }^{17}$

To cement his case against awareness-phenomenology, Coleman (2017) advances an argument against its possibility. Since awareness is always directed at some first-order quality, it is reasonable, he remarks, to expect that we experience the associated awareness-feel as the feel of awareness of this quality rather than merely as a general awareness-feel, non-specific with respect to its object. According to Coleman, this is best accounted for by the fact that the quality targeted by an act of awareness is "phenomenally included" in the awareness-feel

\footnotetext{
17 Coleman (2017, p. 271) allows that we know that we are aware of qualities. This knowledge does not result from awareness being phenomenally manifest but is rather inferred from the fact that-due to our being aware of qualities_qualities are experienced by us.
} 
associated with the act, so that the quality's character is suffused within the awareness-feel. If this were the case though, we would get the quality twice in consciousness: once in a first-order way in virtue of being aware of it and once as part of the awareness-feel associated with our awareness of the quality. Such phenomenal duplication, however, apart from seeming to conflict with the economy of nature, finds no support in Coleman's phenomenology (Coleman 2017, p. 273) — or mine for that matter.

Worse yet, for the proponents of awareness-phenomenology, the alternative looks equally implausible: if the particular awareness-feel does not phenomenologically involve the first-order quality, it's unclear how the act of awareness could be experienced as awareness of this particular quality. It would rather be a sort of general awareness-feel, phenomenally unrelated to the first-order quality, which could hardly be viewed as the feel of our awareness of qualities we are trying to identify.

Coleman thus puts forward a dilemma concerning awareness-phenomenology: either the awareness-feel phenomenally involves the first-order quality and we get phenomenal duplication, or it does not which renders the awareness-feel phenomenally unrelated to the object of the awareness. If Coleman's dilemma is real, we have a principled reason to reject the very possibility of awareness-phenomenology, so to endorse $(\mathrm{F})$.

In my view, this dilemma is a serious challenge for the proponents of awarenessphenomenology which deserves to be addressed and, together with the other considerations in this section, suggests that the existence of awareness-phenomenology is highly controversial. Insofar as Chalmers's argument against panqualityism depends on its existence, then, it is controversial too, hence not decisive. Still, Chalmers is, I shall now argue, right in thinking that the reductive treatment of awareness leads panqualityism into trouble. Importantly, my critique of panqualityism avoids the controversial posit of awareness-phenomenology; instead I'll argue that the reasons why panqualityism cannot bridge the quality-consciousness gap, and so fails as an account of consciousness, have to do with the special nature of our awareness of qualities.

\section{The Quotational Account of Awareness}

To see the worry it will help to first examine the panqualityist approach to awareness as developed by Coleman. While working within the HOT framework, Coleman rejects Rosethal's representational HOT account, holding instead that we are aware of a first-order sensory state in virtue a HOT quoting the state (Coleman 2014, 2015). On this quotational HOT (QHOT) account, we are aware of a quality not due to its being suitably represented by a HOT but due to its being presented or quoted by it. Coleman explains:

I suggest the right higher-order analysis of consciousness sees a $\mathrm{HO}$ state 'quote' a sensory state, forming a larger composite structure wherein the sensory state is displayed. Its being embedded within the HO state and thereby 
displayed is what constitutes the subject's awareness of the sensory state.

(Coleman 2015, pp. 2717-2718)

We are thus to understand awareness in analogy with linguistic quotation. Consider the sentence

\section{S: Jim wrote "cat" in his notebook.}

Here the word between the quotation marks doesn't refer to a meowing four-legged animal, but rather to the word-type it itself tokens, so in a sense to itself. We can thus say that the referent of the quoted word is not represented by the sentence but rather presented by it to the recipient in virtue of being embedded in the quotational context of the sentence. Similarly, Coleman (2015) suggests, awareness consists in our QHOTs presenting our first-order sensory states to the cognitive system in virtue of these states being physically contained in the respective QHOTs and thus quoted by them. The language analogy has its limits: while in S, the token of 'cat' plausibly refers to the word-type it instantiates, awareness is for Coleman a matter of strict token identity between the referring entity and its referent where both roles are occupied by a single quality-instance (Coleman 2015, p. 2718).

The QHOTs which Coleman views as conferring awareness have the following simple form:

This state is present: "

Here the quality in question is embedded in the gap between the quotation marks. Given their simplicity, these QHOTs are viewed by Coleman as mental frames whose sole function is to display the quality - somewhat as a frame in The Louvre displays the Mona Lisa. The framing metaphor captures the idea that, on this theory, QHOTs are indispensable for consciousness: without the "framing" QHOT, the quality would not get displayed as it would remain non-conscious.

QHOT panqualityism aims to accommodate our sense that in being aware of qualities, we have intimate and direct epistemic access to them (Coleman 2014, p. $42 ; 2015$, p. 2723). They are, we feel, "right there" for us, we are aware of them in a more intimate sense than that in which we are aware of objects around us. These we are arguably aware of merely indirectly, our access being mediated by mental representations. It is this experienced immediacy of our access to sensory contents in awareness that provides the theoretical pull to prefer Coleman's QHOT account to the standard HOT account: while the latter relies on representation, according to Coleman, qualities are simply present in the QHOT, and so our access to them would seem to be immediate (Coleman 2019). Hence the QHOT account approximates the Russellian view that we are directly acquainted with qualities (Russell 1912).

Crucially, Coleman's mechanism of awareness, being broadly functional, allows for implementation in physical systems of sufficient complexity (Coleman 2015, p. 2723). Given that panqualityism, as a variety of Russellian monism, "saves" all the physical (i.e. structural) properties of our world, the QHOT mechanism can be 
implemented in a panqualityist world, insofar as the world involves the right sort of organizational structure. So, ex hypothesi, our world instantiates both ingredients that panqualityists recommend for consciousness: qualities and QHOTs about them. If Coleman's theory is correct, then, q-zombies, our qualitative and structural replicas without consciousness, are inconceivable. That would mean that Chalmers's conceivability argument against panqualityism which proceeds from the conceivability of q-zombies to the falsity of panqualityism (see 3) is unsound.

\section{Levine Against the Quotational Account of Phenomenal Concepts}

I shall now argue that, despite its promise, QHOT panqualityism fails to account for awareness of qualities and therefore fails as a theory of consciousness. My critique is based on an objection raised by Joseph Levine (2007) against the popular quotational account of phenomenal concepts. After sketching Katalin Balog's version of the account and introducing Levine's worry, I'll argue that a related challenge applies to QHOT panqualityism.

Balog (2012) aims to resist the step from an explanatory gap between phenomenal and physical truths to dualism by accounting for the gap in physical terms. ${ }^{18} \mathrm{We}$ can say that there is an explanatory gap between phenomenal and physical truths if physical truths leave phenomenal truths unexplained, so that the connection between the two classes of truths appears arbitrary even upon sufficient reflection (Levine 2007). For Balog, the explanatory gap_-far from being a symptom of an ontological gap-results from the nature of our direct phenomenal concepts, which we form in virtue of directly attending to phenomenal states. ${ }^{19}$ According to Balog, direct phenomenal concepts grant us acquaintance with the phenomenal states they refer to in providing us with direct and substantial cognitive access to them. It is, Balog argues, this unique epistemic feature of direct phenomenal concepts which results in the explanatory gap. Since physical concepts do not afford us acquaintance with their referents, any account of phenomenal states in their terms must appear implausible, reasons Balog, making the alleged psycho-physical identities look arbitrary.

Aiming to provide a physicalistic account of acquaintance, Balog suggests that we are acquainted with a phenomenal state in virtue of the state's being a physical constituent part of our direct phenomenal concept of that very state (Balog 2012). In this way, she tells us, the phenomenal state serves as its own mode of presentation and, so to say, presents itself. Balog doesn't describe the part-whole relation in spatial terms, but rather in terms of realisation, suggesting that the phenomenal state is a part of the physical realiser of its phenomenal concept (Balog 2012, p. 25). Since the realisers of non-phenomenal (e.g. physical) concepts are cognitively inaccessible to us, phenomenal concepts are, Balog suggests, exceptional in granting us acquaintance with their own realisers.

According to Levine, Balog's account of acquaintance cannot work. He observes that in being acquainted with phenomenal states these states are cognitively present

\footnotetext{
18 See Papineau (2002) for a similar approach.

19 For more on direct phenomenal concepts see Chalmers (2003).
} 
for us. Levine's term 'cognitive presence' signifies a special cognitive relation which obtains between an organism and its phenomenal state in virtue of the subject's possessing a direct phenomenal concepts of the state (Levine 2007, p. 158). This unique cognitive relation is "more intimate, more substantive, than the kind of relation that obtains between our minds and other items", Levine tells us (2007, p. 159). Thanks to their cognitive presence for us, we know our experiences in a stronger sense than we know, for example, $\mathrm{H}_{2} \mathrm{O}$ molecules, even if we have excellent chemical knowledge, or ordinary objects around us. This means trouble for Balog's account; Levine writes:

[...] we are still owed an account of how physical presence [of the phenomenal state in the phenomenal concept] alone is responsible for cognitive presence. That is, how does the presence of the relevant state within the physical implementation of the representation become something of which we are aware? (Levine 2007, p. 163)

Here Levine suggests that Balog's account of acquaintance faces a new explanatory gap between truths about the physical presence of a phenomenal state in its phenomenal concept, and truths about one's acquaintance with the state: the former just do not explain the latter. Normally, Levine (2007, p. 162) emphasizes, only functional states of a system are relevant to its cognitive properties. Functional states, however, are in principle multiply realizable, which is why the identity of their physical realisers seems irrelevant with respect to the cognitive properties of the cognitive system. It should then be, contra Balog, cognitively irrelevant that the phenomenal concept is partly realised by the phenomenal state it refers to, and so the physical containment of phenomenal states in phenomenal concepts doesn't explain acquaintance.

\section{A New Challenge for Panqualityism}

Levine has formulated, I believe, a powerful challenge for Balog's quotational account of phenomenal concepts. Since Coleman's panqualityism appeals to mental quotation too and Balog's theory is used to illustrate his account (Coleman 2015, p. 2717), one might suspect that a related worry applies to the panqualityist account of awareness. Moreover, Levine's wording in the last quoted passage suggests that his worry concerns awareness more generally. There are crucial differences between the two accounts, to be sure: Firstly, according to Balog, phenomenal concepts quote experiences, not qualities. Unlike Coleman, who aims to explain how we become aware of qualities and thereby become conscious, Balog aims to account for acquaintance with experiences, which are already conscious. Secondly, Balog holds that an experiential sample quoted in a phenomenal concept typically refers to an experience-type, while, for Coleman, a quoted quality always refers to itself-the same token. Still, since both proposals aim to account for immediate awareness of mental contents in terms of these contents' being physically present in concepts or thoughts about them, the suggestion that a worry based on Levine's objection to Balog applies to QHOT panqualityism deserves examining. 
In my view, a challenge based on Levine's indeed applies to QHOT panqualityism and so the following argument can be advanced against the view:

(1) Awareness of qualities involves their cognitive presence for the organism.

(2) QHOT panqualityism cannot account for cognitive presence.

(3) Therefore, panqualityism cannot account for awareness of qualities.

This argument looks valid and, if sound, it proves that QHOT panqualityism cannot account for consciousness since on this view consciousness amounts to awareness of qualities. ${ }^{20}$ However, both premises require support which I shall now try to provide.

It could be objected against premise (1) that for Levine the term 'cognitive presence' is closely associated with 'acquaintance' which is usually understood as an organism's special cognitive relation to its experience, not as a consciousness-constituting relation to qualities. ${ }^{21}$ Moreover, since Levine sometimes ties the issue of cognitive presence with the possession of phenomenal concepts, it may seem that his worry is limited to the sophisticated cognitive situation of reflecting on one's conscious states. Suggesting that consciousness-constituting awareness of qualities involves cognitive presence too, as expressed in (1), can then appear misguided.

There are, however, good reasons to reject this objection against (1). Firstly, notice that in being consciously aware of qualities we seem to be in an immediate and 'intimate' cognitive relation to them. Consider the redness we are aware of when looking at a ripe tomato, the quality seems to be 'right there for us' and we get to know it intimately and in a substantive sense. Our cognitive relation to qualities thus seems more intimate and substantive than that to other objects such as-leaving direct realism aside - ordinary objects or $\mathrm{H}_{2} \mathrm{O}$ molecules. This suggests that awareness of qualities involves cognitive presence of qualities for us and thus supports (1). Moreover, if this consideration is plausible, cognitive presence does not pertain merely to the sophisticated cognitive situation of reflection, but also to pedestrian awareness of qualities - when looking at a ripe tomato, the experienced red quality seems to be intimately present for us even without reflection.

Note also that - as Levine observes in the last quoted passage-cognitive presence of a phenomenal state for a subject requires that the organism is aware of the state. Since it seems reasonable to characterize the sort of awareness which Levine describes here as immediate, substantive and intimate, and it is just this sort of

\footnotetext{
${ }^{20}$ Notice that the present argument doesn't rely on the plausibility of any objection targeting HO approaches as a whole, such as the claim that a non-conscious HOT could not make one conscious of non-conscious sensory content. I remain neutral about the plausibility of these more general objections, focusing rather on a highly unorthodox version of the HOT theory as it is applied to panqualityism. The resulting view faces challenges that differ from those faced by more standard materialist HO theories. For example, a materialist proponents of the HO theories could reply to the conceivability argument in ways that are unavailable to the QHOT panqualityist, as they could allow that zombies are conceivable and question the conceivability-possibility link. The QHOT panqualityist cannot say that as they usually rely on the conceivability-possibility link in their rejection of materialism. I also doubt that materialist HO theorists are committed to cognitive presence of sensory contents.

21 Notice that Levine himself (2019) views acquaintance precisely as a consciousness-constituting relation to sensory qualities and other aspects of the 'virtual world' caused by the computational processes in one's brain. He would thus hardly raise this objection.
} 
awareness that the panqualityists try to account for, it is reasonable to conclude that cognitive presence and immediate, intimate awareness go hand in hand, which lends further support to (1).

Still, it may be objected that since cognitive presence is viewed by Levine as a relation between an organism and its conscious states, not between an organism and its qualities, it's wrong to suppose that it is involved in awareness of qualities. In reply, I suggest that panqualityists can hardly appeal to this objection as they can hardly hold that conscious states are cognitively present for an organism but qualities aren't, since they are committed to the view that conscious phenomenology is exhausted by the phenomenology associated with the qualities we are aware of (see 4). On panqualityism, then, being afforded cognitive presence of our conscious states would simply mean being afforded cognitive presence of qualities. Levine's notion of cognitive presence can thus be, on panqualityism, straightforwardly extended to our awareness of qualities.

I should also mention that Coleman himself (2019) suggests that the panqualityist account of awareness can be used to model acquaintance, viewed as "an especially direct relation we bear to a sensory state, or [...] its sensory qualities, simply in being conscious of it." (Coleman 2019). Moreover, he allows that Levine's objection against Balog may apply against his own view (Coleman, 2019, fn. 91). Both of these points, I take it, lend premise (1) further plausibility.

This last consideration may be taken to suggest that it is only Coleman who is committed to cognitive presence of qualities, while other panqualityists may not be. There is, however, a good reason to think that the commitment to cognitive presence is integral to panqualityism in general. Positing fundamental qualities is a significant metaphysical step which seems to clash with the epistemological view that we do not have any intimate or substantive knowledge of them. If this is our cognitive situation with respect to qualities, we arguably do not know much about what we are adding to our fundamental ontological repertoire. Indeed, it is one of the merits of panqualityism, that we seem to have a very good idea of what qualities are (see 2), which suggests that they are cognitively present for us. If, on the contrary, we do not know qualities fairly intimately and in a substantive sense, it is unclear why we would think they cannot be explained reductively, and so why we shouldn't opt for a non-panqualityist form of Russellian monism or for a materialist view on which qualities are really physical sensory properties, such as the Rosenthal's HOT account (2005).

The notion of cognitive presence is useful in distinguishing the sense in which we are aware of qualities from the weaker sense in which we are aware of other things. I may, for example, be aware in this weaker sense of John's younger sister although I've never met her or seen her photo. It's natural to model this awareness as awareness of the fact that John has a younger sister, although I don't wish to rule out that there may be weak awareness of things too, like when hearing a radio playing in John's younger sister's room makes me indirectly aware of her. ${ }^{22}$ I shall call the cognitive-presence-involving sense in which we are aware of qualities strong awareness

22 See Dretske (1993) for the distinction between consciousness of things and consciousness of facts. 
reserving the term weak awareness for awareness which does not involve cognitive presence. The terms 'cognitive presence' and 'strong awareness' should thus be viewed as two sides of a single coin, capturing the same cognitive relation from two angles: if I am strongly aware of a quality, the quality is cognitively present for me, and vice versa.

A question could be raised as to why do I not simply talk about acquaintance and instead introduce the notion of strong awareness. The reason is that I wish to avoid connotations of the traditional notion of acquaintance. Russell (1912/1976, pp. 51-52) held that through acquaintance we acquire a sort of complete and perfect knowledge of our sense-data, suggesting further that we are acquainted with universals, some deliverances of memory, acts of our own awareness, etc. I wish to remain neutral on these theses and do not think Coleman is committed to these claims. Moreover, I note that some may wish to reserve the notion of acquaintance specifically for situations of (introspective) reflection of one's consciousness and I argued above that we should not limit the scope of strong awareness in this way. ${ }^{23}$

I hope I have rendered (1) plausible. Let me turn to premise (2) which states that QHOT panqualityism cannot account for the cognitive presence of qualities for us. Learning a lesson from Levine, we should ask whether there is an explanatory gap between the physical presence of a quality in a QHOT and the quality's cognitive presence for us. If there is, the quality's cognitive presence for the organism and, as a result, the organism's strong awareness of the quality, remain unexplained.

Why, however, could the physical presence of a quality in a QHOT not help us make sense of its cognitive presence for the organism? ${ }^{24}$ Recall Levine's reasoning against Balog: the identity of a part of the realiser of the QHOT seems irrelevant with respect to the cognitive properties of the system. Coleman's conception, however, differs from Balog's as, according to Coleman, the quality isn't a part of the thought's realiser, but rather literally a physical part of the QHOT, being embedded in it. It is this relation of (physical) embedding that allegedly grounds our awareness of the quality. We thus need to ask whether the embedding of the quality within the QHOT accounts for the fact that the quality is cognitively present for us.

\footnotetext{
${ }^{23}$ It is interesting to ask how far the commitment to the view that our awareness of qualities is strong awareness goes. Above, I argued that it should be accepted by the panqualityists as they seem to be committed to cognitive presence of qualities for us. I also explained why the materialists who view the sensory properties of our consciousness as reducible to physical properties do not share this commitment. I suspect that those thinkers who view phenomenal properties as irreducible would likely accept the commitment to our strong awareness of qualities, insofar as they grant that instantiating a phenomenal property can be analysed as being aware of a quality. Since our awareness-one aspect of instantiating a phenomenal property - is understood as irreducible by these thinkers, they would likely agree with me that the awareness in question is strong awareness. Indeed, Chalmers (2018) may have something like strong awareness in mind when he claims that "the core of the hard problem is posed not by the qualities themselves but by our experience of these qualities: roughly, the distinctive phenomenal way in which we represent the qualities or are conscious of them." Crucially, however, my argument only requires that panqualityists are committed to strong awareness which I have just argued for.

${ }^{24}$ Levine (2007, p. 163) allows that "when we think of a relation such as acquaintance, with its sense of immediacy, metaphorical language about 'sticking the object right in there' irresistibly comes to mind", but—sensibly, I think—rejects the suggestion to take this metaphor literally.
} 
Here I think a worry related to Levine's straightforwardly applies: clearly, the physical presence of the quality within the QHOT is meant to be relevant, but we are owed an explanation as to how and why it constitutes the quality's cognitive presence, which means that we are facing an explanatory gap between truths about the QHOT and truths about strong awareness.

In defence of QHOT panqualityism, it could be suggested that since Coleman (2015) arguably demonstrates that there is an intentional relation between the QHOT and the quality (the QHOT is about the quality in virtue of the quality's being embedded in it) we should allow that the QHOT confers at least weak awareness of the quality. ${ }^{25}$ Given, moreover, that the QHOT does not represent the quality but rather presents it in virtue of containing it (see 5), the awareness in question is arguably direct and so it should count as strong awareness since, it could be suggested, direct awareness brings about the cognitive presence of what we are aware of. According to this suggestion, then, the physical presence of the quality in the QHOT together with relevant intentional facts enables us to explain its cognitive presence for us, which means that the alleged explanatory gap can be closed after all.

I think we should reply to this line of defense that while QHOTs may ground awareness which is direct in the sense of not being mediated by a representation, it is unclear how this awareness could involve cognitive presence of qualities and so constitute our strong awareness of them-recall that strong awareness is defined in terms of cognitive presence, not in terms of directness. The problem is that we would expect that the cognitive properties of the QHOT are exhausted by its intentional properties and yet, the panqualityists clearly need to hold they are not so exhausted, as the QHOT, unlike ordinary representing thoughts, is supposed to ground the cognitive presence of the quality which surely goes beyond the QHOT's intentional properties. Then, however, panqualityists owe us an account of how the physical presence of the quality in the QHOT can determine its cognitive properties. It won't help here to say that its physical presence (partially) grounds the thought's intentional properties as it is unclear why this fact about how intentional properties are grounded results in the quality's cognitive presence for us. So we are once again faced with an explanatory gap between facts about the QHOT and facts about awareness, which gives us a good reason to view the sort of awareness which QHOTs ground as at best weak awareness despite the fact that it is non-representational and in that sense direct. This line of defense thus looks ineffective.

This completes my case for premise (2) of the argument expressed above. Together its two premises lead to the conclusion that QHOT panqualityists cannot account for our awareness of qualities, which I characterized as strong awareness, being as it involves cognitive presence.

\footnotetext{
25 Rosenthal (1997) and others hold that HOTs confer awareness of their referents - first-order sensory states. See e.g. Block (1995), Chalmers (1996, p. 29) for the suggestion that intentionality grounds a sort of cognitive access to what our mental representations are intentionally related to.
} 


\section{Strong-Awareness Zombies}

With this result in mind, the following conceivability argument against QHOT panqualityism can be formulated. Here $Q Q$ stands for the set of all truths about qualityinstances in conjunction with structural truths, and $A$ stands for an arbitrary truth about strong awareness, such as "Jane is strongly aware of a reddish quality".

(1) $Q Q \& \sim A$ is conceivable.

(2) If $Q Q \& \sim A$ is conceivable, it is possible.

(3) If $Q Q \& \sim A$ is possible, panqualityism is false.

(4) Panqualityism is false.

Since the step from conceivability to possibility in (2) can hardly be challenged by the panqualityists, the key premise is (1). It can be illustrated in terms of the conceivability of strong-awareness zombies (A-zombies), our exact replicas with respect to both the qualities instantiated and the structural properties constituting the QHOT mechanism, who aren't strongly aware of any quality. If, however, as I argued, QHOT panqualityists are committed to holding that consciousness involves strong awareness of qualities, the conceivability of $A$-zombies implies that the panqualityist account of consciousness is lacking and the view fails. ${ }^{26}$ Notice that the conceivability of A-zombies is compatible with the inconceivability of weak-awareness zombies, creatures instantiating qualities and weak awareness of them. If weak awareness is reducible to mental representation, weak-awareness zombies are arguably inconceivable as their structural properties ground the relevant representational properties. Chalmers's q-zombies, our qualitative replicas without awareness, are thus inconceivable, if we have only weak awareness in mind. If I am right, however, instantiating qualities and weak awareness of them does not suffice for consciousness.

\section{Other Forms of Panqualityism}

The sceptical conclusion reached so far is confined to QHOT panqualityism and allows that other varieties of panqualityism may be more plausible. Could panqualityists turn somewhere else than to the QHOT theory to get around the worry concerning cognitive presence?

\footnotetext{
${ }^{26}$ In a footnote, Coleman suggests a way to resist the conceivability of q-zombies which, I think, also applies to A-zombies. He argues that q-zombies are inconceivable because they instantiate the very same sensory qualities as their conscious twins (Coleman 2017, p. 278, fn. 73). He, however, does not offer a clear explanation as to why the conceivability of q-zombies requires that they are sensorily different from their conscious twins which is why I shall disregard this line of defense here.
} 
They could turn to a non-quotational version of representationalism. Representationalism splits into first-order representationalism (FOR) and higher-order representationalism (HOR). According to FOR, defended by Tye (1995), Dretske (1995) and others, phenomenal properties are reducible to representational properties. This, however, goes directly against the spirit of panqualityism, which views the qualitative nature of phenomenal properties as irreducible, and so FOR is unlikely to help here. ${ }^{27}$ A classic version of HOR is Rosenthal's HOT theory of which Coleman's theory is an unorthodox version. Unlike Coleman, the classic varieties of HOR account for awareness of sensory contents-unsurprisingly-in representational terms, ${ }^{28}$ which means that our cognitive access to conscious contents would be indirect at best as our cognitive access to the represented sensory content is mediated by the representing HOT. But such indirectness of our cognitive access to qualities seems to rule out their cognitive presence for us and thus also our strong awareness of qualities. Classic HOR is therefore of no help either. ${ }^{29}$

Panqualityists could turn to Kriegel's self-representationalism to account for awareness. According to this theory, usually viewed as an unorthodox variety of HOR, conscious states are complex wholes which have a sensory part and a representing part where the latter directly represents the former and indirectly represents the whole conscious state (Kriegel 2009). Since, however, the main mechanism which self-representationalism appeals to is, once again, representation, then if, as I argued, strong awareness cannot be accounted for in representational terms and thus modelled as providing merely indirect cognitive access to its contents, self-representationalism is unlikely to help panqualityists either.

This consideration completes my case against panqualityism in its orthodox form, which combines non-reductionism about qualities with a reductionism about awareness, since I have considered, to my best knowledge, all the theoretical options available for a reduction of awareness, and none seems capable of accounting for our strong awareness of qualities. Moving away from orthodoxy, one could envision forms of panqualityism which adopt a less deflationary approach to awareness. Perhaps qualities, without involving full-fledged microsubjects, already involve instances of proto-awareness. The idea behind this view, which we can call protoawareness panqualityism, is that once qualities are appropriately organised, the instances of proto-awareness inherent to each of these qualities jointly produce fullfledged awareness. The challenge for a view of this sort is to explain what sort of organization is needed for awareness to be produced and why it is just this sort of organization (Chalmers 2017, p. 203). This challenge is far from trivial.

One way to avoid the described challenge is to adopt emergent panqualityism according to which strong awareness is a brute emergent feature of complex cognitive systems implemented by configurations of qualities. ${ }^{30}$ One worry about this

\footnotetext{
27 Notice that even if representational properties which FOR posits were intrinsically qualitative, we would still lack an account of how we become aware of their intrinsic redness.

28 Feigl's remarks quoted in ii. seem to gesture towards a view of this sort.

29 Coleman (2014) is sceptical about the prospects of the ordinary HOT theory to account for our awareness of sensory qualities.

30 This suggestion is inspired by Levine's $(2007,2019)$ remarks about a brute acquaintance relation.
} 
view is that it seems incompatible with awareness playing a causal role in the physical world. Attributing a causal role to emergent awareness is arguably incompatible with the principle of completeness of physics (see 1). Intuitively, however, the fact that we are aware of qualities has causal effects in the world. It is, furthermore, unclear whether this view would have any merits over classic emergentism, which doesn't posit fundamental qualities.

\section{Conclusion}

I have argued that Chalmers's critique of panqualityism rests on the controversial thesis that there is awareness phenomenology, and I offered a critique of the view which does not rely on this thesis. In particular, I have argued that Coleman's QHOT panqualityism fails to account for consciousness because it faces its own explanatory gap between the relevant sort of awareness of qualities, which I have called strong awareness, and the QHOT mechanism that is meant to account for it. This means that Coleman's panqualityism is susceptible to a version of the conceivability argument, the A-zombie argument, which appeals to the conceivability of qualitative and structural replicas of us which lack strong awareness of qualities (hence A-zombies). I have further argued that my critique generalizes to all orthodox forms of panqualityism that provide a reductive account of awareness. I have also briefly considered two unorthodox versions of panqualityism which treat awareness in a non-reductive manner, but argued that they face considerable challenges. I conclude, then, that despite its initial appeal, panqualityism does not look very promising upon reflection.

Acknowledgements I completed this paper as part of The Consciousness and Matter Project funded from the European Structural and Investment Funds. I am grateful to audiences at the Russellian Monism: Time for the Details conference at CEU in Budapest, at the First Bochum Grad Workshop in Philosophy of Mind and of Cognitive Science, at the University of Hertfordshire and at the Czech Academy of Sciences, Institute of Philosophy where I presented versions of this material. The paper has greatly benefited from the written or spoken comments of Barbara Gail Montero, Luke Roelofs, Tomáš Hř́bek, Greg Miller, James Hill, Juraj Hvorecký, Tomáš Marvan, Brice Bantegnie and the two anonymous reviewers of this journal. Special thanks to Sam Coleman for his detailed comments on multiple drafts of the paper.

Open Access This article is licensed under a Creative Commons Attribution 4.0 International License, which permits use, sharing, adaptation, distribution and reproduction in any medium or format, as long as you give appropriate credit to the original author(s) and the source, provide a link to the Creative Commons licence, and indicate if changes were made. The images or other third party material in this article are included in the article's Creative Commons licence, unless indicated otherwise in a credit line to the material. If material is not included in the article's Creative Commons licence and your intended use is not permitted by statutory regulation or exceeds the permitted use, you will need to obtain permission directly from the copyright holder. To view a copy of this licence, visit http://creativecommons.org/licen ses/by/4.0/. 


\section{References}

Alter, T., \& Nagasawa, Y. (2015). What is Russellian monism? In T. Alter \& Y. Nagasawa (Eds.), Consciousness in the physical world: Perspectives on Russellian monism (pp. 422-451). New York: Oxford University Press.

Balog, K. (2012). Acquaintance and the mind-body problem. In S. Gozzano \& C. S. Hill (Eds.), New Perspectives on type identity: The mental and the physical. Cambridge: Cambridge University Press.

Block, N. (1995). On a confusion about a function of consciousness. Behavioural and Brain Sciences, 18(2), 227-247.

Chalmers, D. (1995). The puzzle of conscious experience. Scientific American, 237(6), 62-68.

Chalmers, D. (1996). The conscious mind: In search of a fundamental theory. New York: Oxford University Press.

Chalmers, D. (2003). The content and epistemology of phenomenal belief. In Q. Smith \& A. Jokic (Eds.), Consciousness: New philosophical perspectives. New York: Oxford University Press.

Chalmers, D. (2010). The character of consciousness. Oxford: Oxford University Press.

Chalmers, D. (2013). The contents of consciousness: Reply to Hellie, Peacocke and Siegel. Analysis, 73(2), 345-368.

Chalmers, D. (2015). Panpsychism and panprotopsychism. In T. Alter \& Y. Nagasawa (Eds.), Consciousness in the physical world: Perspectives on Russellian monism (pp. 246-276). New York: Oxford University Press.

Chalmers, D. (2017). The combination problem for panpsychism. In L. Jaskolla (Ed.), G Brüntrup (pp. 179-214). Panpsychism. Contemporary perspectives. New York: Oxford University Press.

Chalmers, D. (2018). The metaproblem of consciousness. Journal of Consciousness Studies, 25(9-10), 6-61.

Coleman, S. (2012). Mental chemistry: Combination for panpsychists. Dialectica, 66(1), 137-166.

Coleman, S. (2014). The real combination problem: Panpsychism, micro-subjects, and emergence. Erkenntnis, 79(1), 19-44.

Coleman, S. (2015). Quotational higher-order thought theory. Philosophical Studies, 172(10), 2705-2733.

Coleman, S. (2017). Panpsychism and neutral monism: How to make up one's mind. In G. Brüntrup \& L. Jaskolla (Eds.), Panpsychism: Contemporary perspectives (pp. 518-596). New York: Oxford University Press.

Coleman, S. (2019). Natural acquaintance. In J. Knowles \& T. Raleigh (Eds.), Acquaintance: New essays (pp. 49-74). Oxford: Oxford University Press.

Dennett, D. (1991). Consciousness explained. Boston: Little Brown.

Dretske, F. (1993). Conscious experience. Mind, 102(406), 263-283.

Dretske, F. (1995). Naturalizing the mind. Cambridge: MIT Press.

Feigl, H. (1958/1967). The "mental" and the "physical". Minnesota Studies in the Philosophy of Science 2, 370-497. Reprinted (with a postscript) as The "Mental" and the "Physical". Minneapolis: University of Minnesota Press.

Gennaro, R. J. (2008). Representationalism, peripheral awareness and the transparency of experience. Philosophical Studies, 139(1), 39-56.

Goff, P. (2009). Why panpsychism doesn't help us explain consciousness. Dialectica, 63(3), 289-311.

Goff, P. (2015). Against constitutive Russellian monism. In T. Alter \& Y. Nagasawa (Eds.), Consciousness in the physical world: Perspectives on Russellian monism (pp. 370-400). New York: Oxford University Press.

Goff, P. (2017). Consciousness and fundamental reality. New York: Oxford University Press.

James, W. (1890). The principles of psychology. New York: Henry Holt.

Kriegel, U. (2009). Subjective consciousness: A self-representational theory. Oxford: Oxford University Press.

Levine, J. (2007). Phenomenal concepts and the materialist constraint. In T. Alter \& S. Walter (Eds.), Phenomenal concepts and phenomenal knowledge: New essays on consciousness and physicalism (pp. 145-166). New York: Oxford University Press.

Levine, J. (2019). Acquaintance is consciousness and consciousness is acquaintance. In J. Knowles \& T. Raleigh (Eds.), Acquaintance: New Essays (pp. 33-48). Oxford: Oxford University Press.

Mach, E. (1959). The analysis of sensations. New York: Dover. 
McClelland, T. (2013). The Neo-Russellian ignorance hypothesis. A hybrid account of phenomenal consciousness. Journal of Consciousness Studies, 20(3-4), 125-151.

Montague, M. (2017). What kind of awareness is awareness of awareness? Grazer Philosophische Studien, 94(3), 359-380.

Moore, G. E. (1903). The refutation of idealism. Mind, 12(48), 433-453.

Nagel, T. (1974). What is it like to be a bat? Philosophical Review, 83(4), 435-450.

Papineau, D. (2002). Thinking about consciousness. New York: Oxford University Press.

Rosenberg, G. (2004). A place for consciousness: Probing the deep structure of the natural world. Oxford: Oxford University Press.

Rosenthal, D. M. (1997). A theory of consciousness. In N. Block, O. Flanagan, \& G. Güzeldere (Eds.), The nature of consciousness: Philosophical debates (pp. 729-753). Cambridge: The MIT Press.

Rosenthal, D. M. (2005). Consciousness and mind. Oxford: Oxford University Press.

Russell, B. (1912/1976). The Problems of Philosophy. London: Oxford University Press.

Russell, B. (1954). The analysis of matter. New York: Dover Publications.

Seager, W. (2006). The "intrinsic nature" argument for panpsychism. Journal of Consciousness Studies, 13(10-11), 129-145.

Stoljar, D. (2001). Two conceptions of the physical. Philosophy and Phenomenological Research, 62(2), 253-281.

Stoljar, D. (2014). Four kinds of Russellian monism. In U. Kriegel (Ed.), Current controversies in philosophy of mind (pp. 17-39). New York and London: Routledge.

Strawson, G. (2006). Realistic monism: Why physicalism entails panpsychism? Journal of Consciousness Studies, 13(10-11), 3-31.

Strawson, G. (2017). Self-Intimation. In The Subject of Experience (pp. 137-164). Oxford: Oxford University Press.

Tye, M. (1995). Ten problems of consciousness. Cambridge: MIT Press.

Zahavi, D. (1999). Self-awareness and alterity: A phenomenological investigation. Evanston: Northwestern University Press.

Publisher's Note Springer Nature remains neutral with regard to jurisdictional claims in published maps and institutional affiliations. 